\title{
Paediatric virology as a candidate of paediatric subspecialisation: An interview with Assistant Professor of Molecular Microbiology-Virology Angeliki Melidou
}

\author{
IOANNIS N. MAMMAS and DEMETRIOS A. SPANDIDOS \\ Department of Clinical Virology, School of Medicine, University of Crete, Heraklion 71003, Greece
}

Received June 22, 2018; Accepted July 23, 2018

DOI: $10.3892 /$ etm.2018.6545

\begin{abstract}
According to Professor Angeliki Melidou, Assistant Professor of Molecular Microbiology-Virology at the School of Medicine of the Aristotle University of Thessaloniki in Greece, recent advances in modern virology have important implications in the successful clinical management of neonatal and paediatric viral infections. On the other hand, preventive measures for infectious diseases and their complications, including vaccinations, proper regular examinations and early diagnosis, are equally crucial. Molecular genetics reveals a new era both in the detection of viral infections and in following up the infection and treatment, as well as identifying genetic predisposition that would affect disease course and outcome. Professor Melidou supports that paediatric virology as a candidate of paediatric subspecialisation would definitely play an important role in preparing specialised medical scientists. These scientists would be properly educated for the management of emerging and re-emerging viral infections, treatment options and schemes according to children's special needs, available prevention strategies and diagnostic capacities. In the context of the '4th Workshop on Paediatric Virology', Professor Melidou's lecture will focus on the epidemiology of influenza virus types and subtypes in childhood.
\end{abstract}

\section{Contents}

1. Introduction

2. Questions and Answers

\section{Introduction}

Professor Angeliki Melidou (Fig. 1), Assistant Professor of Molecular Microbiology-Virology at the School of Medicine

Correspondence to: Professor Demetrios A. Spandidos, Department of Clinical Virology, School of Medicine, University of Crete, Heraklion 71003, Greece

E-mail: spandidos@spandidos.gr

Key words: virology, paediatric virology, influenza, workshop, Professor Angeliki Melidou, Aristotle University of the Aristotle University of Thessaloniki, was born in 1979 in Thessaloniki, Greece. She went to Arskakio Gymnasium and Lyceum, from where she graduated in 1996. She studied biology at the School of Biology and Biochemistry at the University of Bath in the UK and acquired her MSc in human reproductive biology from Imperial College of Medicine, Technology and Science in London in 2001. She worked as a scientific adviser at a molecular biology company in London for one year and she then returned to Greece in 2002, where she began her PhD at the Microbiology Department at the School of Medicine of the Aristotle University of Thessaloniki in Greece. The subject of her dissertation focused on molecular epidemiology and antiviral resistance of influenza A viruses (1). She finished her $\mathrm{PhD}$ in 2008 with distinction. Since 2004 she has organised and managed the Molecular Department of the National Influenza Centre for Northern Greece and the Second Laboratory of Microbiology of the Aristotle University of Thessaloniki. Her department has since then acquired ISO15189 for molecular diagnostic methods for influenza and is nowadays equipped with state-of-art scientific equipment for genetic analysis of viruses e.g. next-generation sequencing (NGS).

She was elected lecturer in Molecular MicrobiologyVirology at the School of Medicine of the Aristotle University of Thessaloniki in 2012 and Assistant Professor of Molecular Microbiology-Virology in 2014, involved with the academic education of 3rd year medical students since 2004. She is a member of national and international scientific societies and of the European (ERLI-net) and Global (GISRS) influenza networks. In 2016, she was selected as a national expert at the European Commission agency of the European Centre for Disease Prevention and Control (ECDC), and she relocated to Stockholm in Sweden until September 2017. During her stay, she was involved in the European surveillance of influenza. She has over 167 published materials in national and international journals and conferences (2-15).

To date, Professor Melidou has helped, supported and advised the Paediatric Virology Study Group (PVSG) and has been member of its academic advisory board. In 2016, her lecture at the '2nd Workshop on Paediatric Virology' was entitled 'influenza in childhood: a usual suspect' (16), while in 2017, at the '3rd Workshop on Paediatric Virology', she presented an overview of the evidence, limitations and proposals on live-attenuated intranasal influenza vaccination (LAIV) in 
children (17). In September 22nd, 2018, in the context of the '4th Workshop on Paediatric Virology', Professor Melidou will focus on the epidemiology of influenza virus types and subtypes in childhood.

\section{Questions and Answers}

Question: Dear Professor Angeliki Melidou, first of all thank you for all your support, your advice and your help. As one of the key lecturers of the '2nd' and the '3rd Workshop on Paediatric Virology', which was held in Athens in 2016 and 2017, respectively, we would like to have your evaluation and comments on this scientific event. How could we improve this workshop?

Answer: The course had distinct scientists, both MDs and virologists from Greece and abroad, sharing their knowledge, expertise and the latest scientific information on their fields. Various topics were covered, which on one hand is very interesting, on the other hand the workshop could also gain from a more focused and in-depth analysis of a special theme selected each year. A wider communication and promotion of the workshop, to attract more virologists and other scientists from the academic sector as participants would also be important, so that we come closer to our 'academic' goal.

Question: Paediatric virology is an exciting field exploring new knowledge of neonatal and paediatric viral infections and how to detect, manage and treat them. According to your scientific background, what advances over the past years do you consider the most significant in the field of paediatric viral infections?

Answer: Recent advances in neonatal and paediatric viral infections on the aetiology, diagnosis and therapeutic treatment of common and rare conditions have important implications in their successful clinical management. On the other hand, preventive measures of infectious diseases and their complications, including vaccinations, proper regular examinations and early diagnosis, are equally crucial. The recent advances in molecular genetics also reveals a new era both in the detection of viral infections and in following-up the infection and treatment, as well as identifying genetic predisposition that would affect disease course and outcome.

Questions: Detection of viral infections using molecular techniques is interestingly expanding. What are the most significant challenges that remain to be solved regarding molecular virology diagnostics? How could general paediatricians be involved in the induction of molecular tests into their clinical practice?

Answer: Molecular diagnostic tests in virology are indeed expanding and dominate the diagnosis of viral infections. Multiplex panels have an important advantage, as they aid syndromic diagnosis (i.e., based on the patient symptoms) and can identify a variety of pathogens, as well as co-infections. A significant challenge would be to identify which of the detected microbes are the etiologic factors. This is also the case with the new whole genome sequencing (WGS) approaches; with this technique, we have the possibility to identify every single virus (and bacterium) in any given sample, even in undiagnosed cases, of unknown aetiology. This

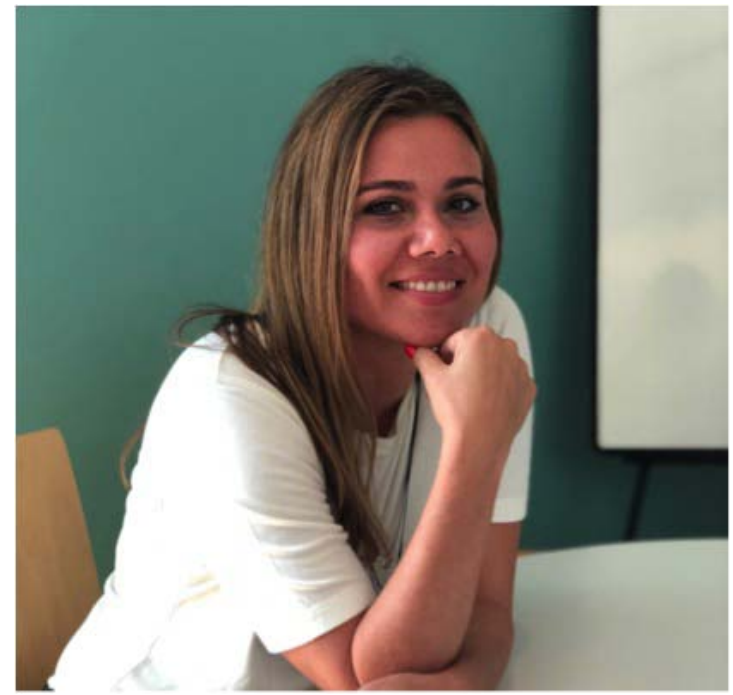

Figure 1. Professor Angeliki Melidou, Assistant Professor of Molecular Microbiology-Virology at the School of Medicine of the Aristotle University of Thessaloniki in Greece, and invited lecturer at the "4th Workshop on Paediatric Virology', Athens, Greece.

is crucial and can be easily interpretable in cases of sterile samples (e.g., cerebrospinal fluid), but interpretation can be very tricky in cases of non-sterile samples (e.g., pharyngeal aspirate). I believe that it is crucial for paediatricians to have a background on what are molecular techniques, what they can ask for in terms of diagnostic tests and how to interpret a result.

Question: Paediatric virology has recently been proposed as a new candidate of paediatric subspecialisation (18). Both paediatric clinicians and basic scientists have been proposed to possess a critical educational role on this. I would like to have your opinion on the future role of paediatric virology as a paediatric subspecialty.

Answer: Paediatric virology as a candidate of paediatric subspecialisation would definitely play an important role in preparing specialised medical scientists. These scientists would be properly educated for the management of emerging and re-emerging viral infections, treatment options and schemes according to the special needs of the patient (e.g., neonate, immunocompromised), available prevention strategies and diagnostic capacities. The most relevant medical subspecialisation is now the infectious diseases specialisation in internal medicine and off course the paediatric infectious diseases subspecialty in paediatrics. Paediatrics and infectious diseases (and/or virology) is even more dedicated to best treating our children.

Question: In your last lecture, you addressed the topic of intranasal vaccination against influenza (17). How close are we to introduce the intranasal way of influenza vaccine's administration into the current paediatric clinical practice?

Answer: LAIV for influenza is an important way of vaccination and could potentially serve in a case of a pandemic. During seasonal influenza seasons, it is equally important because it facilitates mass children vaccination that induces indirect protection to the elderly and other high-risk individuals. There is an ongoing discussion in Greece about 
influenza vaccination in children, which is not mandatory at the moment. However, due to the increased cost, I am not sure that there is the capacity of such an intervention nowadays. We await the UK publications on their preliminary results from their LAIV programme in children, as well as US decision on whether they will continue or discontinue LAIV vaccination in the future.

Question: Your research interest is focused on influenza. Could you present us briefly your recent achievements on this field? Answer: Indeed my research interest is on the influenza virus. I have worked with influenza since 2004, mainly focusing on the genetic analysis of the viruses that circulate in Greece to identify antigenic variants and mutations possibly affecting the pathogenicity of the viral strains. For the past two years, through my collaboration with the ECDC, I am working on the molecular surveillance of influenza at a European level, trying to aid in the World Health Organization (WHO) recommendation of the influenza vaccine composition each year.

Question: Recently you published your work on your contribution of surveillance data from WHO European Region (2). What obstacles did you manage while you were collecting surveillance data on influenza in Greece? Could you describe to us your recent collaboration with Sweden?

Answer: Influenza surveillance in Greece is a very well designed field. It is coordinated by the Hellenic Center for Disease Control and Prevention (KEELPNO) and there are two national influenza centres that perform the detection, culture and molecular and antigenic analyses of circulating strains, one in northern Greece at the Microbiology Department of the School of Medicine of the Aristotle University of Thessaloniki and one in south Greece at Pasteur Institute in Athens. There are also other collaborating centres, like the Microbiology Department of University of Athens. The laboratory results are reported weekly at KEELPNO and ECDC/WHO. Due to the financial crisis, there is always the budget issue, but gladly it has not compromised our work so far. Last year I had the pleasure of being in Sweden at ECDC, as a seconded national expert and after May 1, I will relocate there as an expert in influenza in the surveillance and response unit. From this post I hope to assist our country as much as I can.

Question: You are currently the youngest academic virologist in Greece. How difficult is for you to work as a virologist in a country under continuous financial crisis? What challenges have you managed to date in your University and how did you overcame them?

Answer: The University, similar to the whole country, is under a financial crisis the past years. Our laboratory always aims to attract European projects, so that we can cope with our research needs. Thankfully, as you said, I am still relatively young and able to travel to increase our collaboration with other European partners, which I think is an important step in overcoming our current barriers.

Question: Your laboratory under the direction by Professor Anna Papa, Professor of Microbiology and Director of the Department of Microbiology at the School of Medicine of the Aristotle University of Thessaloniki, is a reference virology laboratory with a great reputation and experience in diagnostics and molecular epidemiology of arboviruses and haemorrhagic fever viruses in Greece. What is the field of your lab's expertise in total? Among your lab's achievements in virology, which ones do you consider as the most significant?

Answer: Our laboratory, under the direction of Professor Anna Papa, a well-known scientist in the field of virology, at the Microbiology Department at the School of Medicine, is indeed one of the leading virology laboratories in Greece. Among other diagnostic services, we host three national centres in virology, as you said the arboviruses and haemorrhagic fever, the influenza and the HIV centres. We provide surveillance and diagnosis of viral infections and we are using conventional as well as state-of-art techniques. Our laboratory is also an educational centre, providing training not only to Greek medical students in the field of microbiology, but also to European partners in the field of influenza.

Question: Thank you for answers. We are looking forward to your lecture at the '4th Workshop on Paediatric Virology' on the epidemiology of influenza virus types and subtypes in childhood. We are also looking forward to your message as a virologist on the 100 years anniversary of the 'Spanish' influenza pandemic in 1918, which devastated one third of the population of Skyros island (19).

\section{References}

1. Melidou A: Molecular analysis and antiviral resistance of influenza A viruses isolated in N. Greece (Doctoral Thesis). Aristotle University of Thessaloniki, Thessaloniki, 2008 (In Greek).

2. Predominance of influenza $\mathrm{A}(\mathrm{H} 3 \mathrm{~N} 2)$ virus genetic subclade 3C.2a1 during an early 2016/17 influenza season in Europe-Contribution of surveillance data from World Health Organization (WHO) European Region to the WHO vaccine composition consultation for northern hemisphere 2017/18. Vaccine 35: 4828-4835, 2017.

3. Melidou A, Gioula G, Exindari M, Ioannou E, Gkolfinopoulou K, Georgakopoulou T, Tsiodras S, Papa A. and Influenza A: (H3N2) genetic variants in vaccinated patients in northern Greece. J Clin Virol 94: 29-32, 2017.

4. Broberg E, Melidou A, Prosenc K, Bragstad K, Hungnes O and European WHO: Region and the European Influenza Surveillance Network members of the reporting countries. Predominance of influenza $\mathrm{A}(\mathrm{H} 1 \mathrm{~N} 1) \mathrm{pdm} 09$ virus genetic subclade $6 \mathrm{~B} .1$ and influenza B/Victoria lineage viruses at the start of the 2015/16 influenza season in Europe. Euro Surveill 21: pii: 30184, 2016.

5. Melidou A, Gioula G, Exindari M, Chatzidimitriou D and Malisiovas N: Genetic analysis of post-pandemic 2010-2011 influenza $\mathrm{A}(\mathrm{H} 1 \mathrm{~N} 1) \mathrm{pdm} 09$ hemagglutinin virus variants that caused mild, severe, and fatal infections in Northern Greece. J Med Virol 87: 57-67, 2015.

6. Melidou A, Exindari M, Gioula G and Malisiovas N: Severity of the two post-pandemic influenza seasons 2010-11 and 2011-12 in Northern Greece. Hippokratia 17: 150-152, 2013.

7. Gioula G, Melidou A, Exindari M, Chatzopoulou E, Chatzidimitriou D and Malisiovas N: Laboratory surveillance of influenza virus in children under 10 years old, in northern Greece, during 2004-2010. Hippokratia 17: 17-19, 2013.

8. Gioula G, Melidou A, Exindari M, Chatzidimitriou D and Malisiovas N: H275Y oseltamivir resistant Influenza A (H1N1) strains in northern Greece during the post pandemic influenza season 2010-2011. Hippokratia 16: 384, 2012.

9. Gioula G, Melidou A, Exindari M, Papoutsi N, Chatzidimitriou D, Dotis J and Malisiovas M: Oseltamivir-resistant influenza A pandemic (H1N1) 2009 virus in Northern Greece. Hippokratia 15: 272-274, 2011.

10. Melidou A, Gioula G, Pogka V, Exindari M, Moutoussi A, Sgouras D, Papadakos K, Chatzidimitriou D, Karabaxoglou D, Mentis A, et al: Molecular and phylogenetic analysis of Greek measles 2010 strains. Epidemiol Infect 140: 432-438, 2012. 
11. Melidou A, Gioula G, Exindari M, Chatzidimitriou D, Diza E and Malisiovas N: Molecular and phylogenetic analysis of the haemagglutinin gene of pandemic influenza H1N1 2009 viruses associated with severe and fatal infections. Virus Res 151: 192-199, 2010.

12. Melidou A, Exindari M, Gioula G, Chatzidimitriou D, Pierroutsakos Y and Diza-Mataftsi E: Molecular and phylogenetic analysis and vaccine strain match of human influenza $\mathrm{A}(\mathrm{H} 3 \mathrm{~N} 2)$ viruses isolated in Northern Greece between 2004 and 2008. Virus Res 145: 220-226, 2009.

13. Melidou A, Gioula G, Exindari M, Chatzidimitriou D, Diza Mataftsi E and Influenza A: (H5N1): an overview of the current situation. Euro Surveill 14: pii: 19216, 2009.

14. Melidou A: Avian influenza A(H5N1)--current situation. Euro Surveill 14: pii: 19199, 2009.

15. Melidou A, Kyriazopoulou V, Diza E, Alexiou S and Pierroutsakos Y: Antiviral resistance of influenza A (H3N2) strains isolated in northern Greece between 2004 and 2007. Euro Surveill 14: pii: 19104, 2009.

16. Mammas IN, Theodoridou M, Kramvis A, Thiagarajan $P$, Gardner S, Papaioannou G, Melidou A, Koutsaki M, Kostagianni G, Achtsidis V, et al: Paediatric Virology: A rapidly increasing educational challenge. Exp Ther Med 13: 364-377, 2017.
17. Mammas IN,Greenough A, Theodoridou M,Kramvis A,Rusan M, Melidou A, Korovessi P, Papaioannou G, Papatheodoropoulou A, Koutsaftiki C, et al: Spandidos DA. Paediatric Virology and its interaction between basic science and clinical practice (Review). Int J Mol Med 41: 1165-1176, 2018.

18. Mammas IN, Greenough A, Theodoridou M and Spandidos DA: Paediatric Virology: A new paediatric subspecialty? A proposal at the Workshop on Paediatric Virology, Athens, October 10 , 2015. Exp Ther Med 11: 3-5, 2016.

19. Mammas IN, Theodoridou M and Spandidos DA: The 1918 Spanish flu outbreak that devastated a Greek island underlines past lessons that must never be forgotten. Acta Paediatrica: Mar 31, 2018 (Epub ahead of print). doi: 10.1111/apa.14351.

This work is licensed under a Creative Commons Attribution-NonCommercial-NoDerivatives 4.0 International (CC BY-NC-ND 4.0) License. 